\title{
Genotypic and Seasonal Variation in Plant Development and Yield Attributes in Tomato (Lycopersicon esculentum Mill.) Cultivars
}

\begin{abstract}
Morphological attributes and yield of eight genotypes of tomato namely, J-5, Binatomato-5, BARItomato-7, CLN-2026, CLN-2366, CLN-2413, CLN-2418 and CLN-2443 were studied over three seasons. Effects of seasonal and genotypic variations and their combination on plant height, number of primary branches per plant, number of flower clusters per plant, number of fruit clusters per plant, number of fruits per plant, individual fruit weight, fruit yield were significant. Fruit yield and almost all the morphological attributes of tomato genotypes were at peak in winter followed by pre-winter and summer season. Over three seasons, the genotype CLN-2413 produced the highest fruit yield followed by BARI tomato7 producing the tallest plants with maximum number of primary branches and the highest number of fruits per plant. The genotypes Binatomato-5, CLN-2026 and CLN-2418 ranked 3rd and CLN-2366 and CLN-2443 ranked 4th with respect to yield performance. The genotype J-5 produced the lowest number of fruits per plant and fruit yield. In winter, fruits number and yield were highest in CLN-2413 while BARI tomato-7 carried the statistically same rank.
\end{abstract}

Keyword: Tomato, yield, yield attributes, growing seasons 